Historic, Archive Document

Do not assume content reflects current scientific knowledge, policies, or practices. 

$6289 \mathrm{ma}$
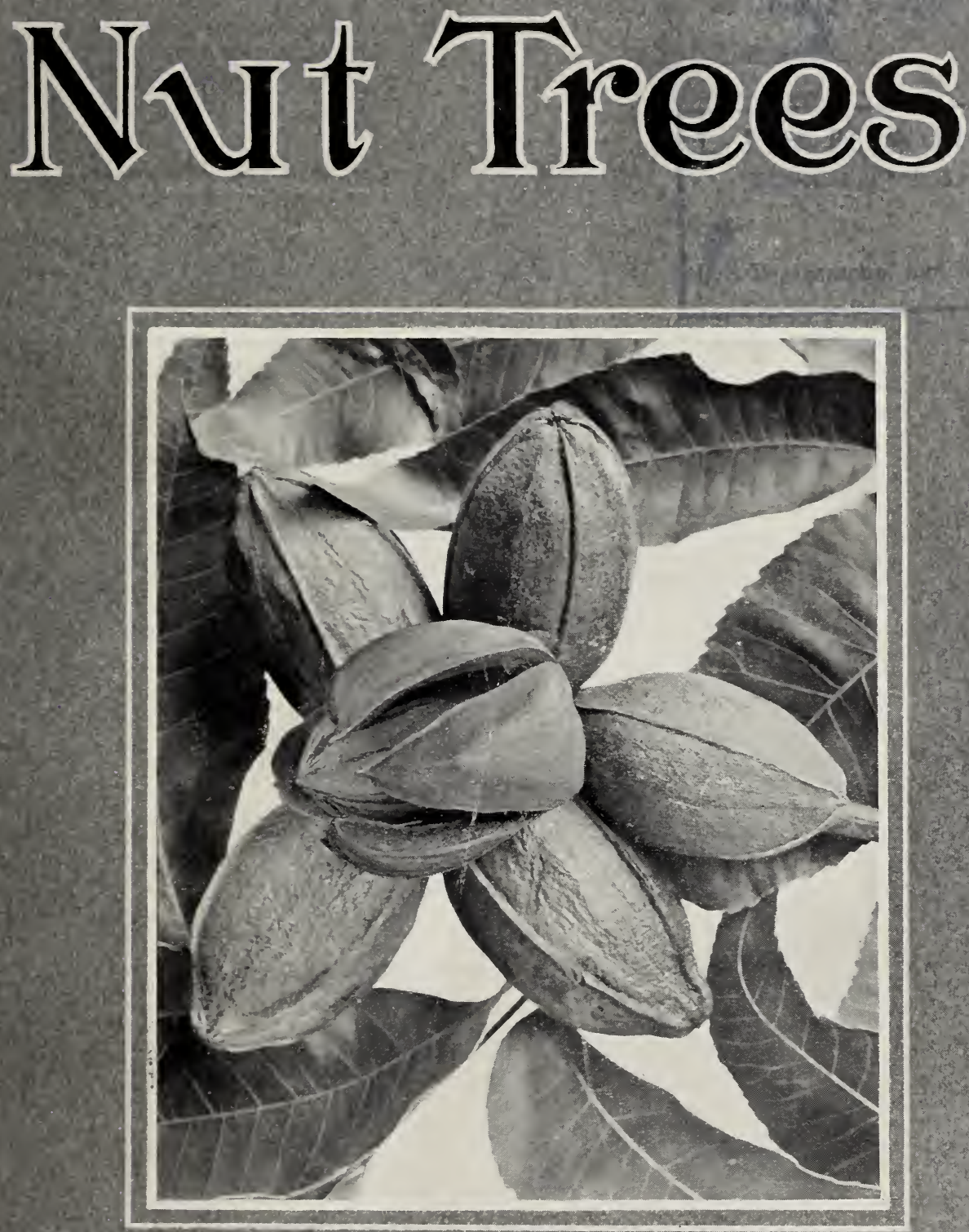

ARROWFIELD NURSERIES ii i

Petersburg, Virginia 


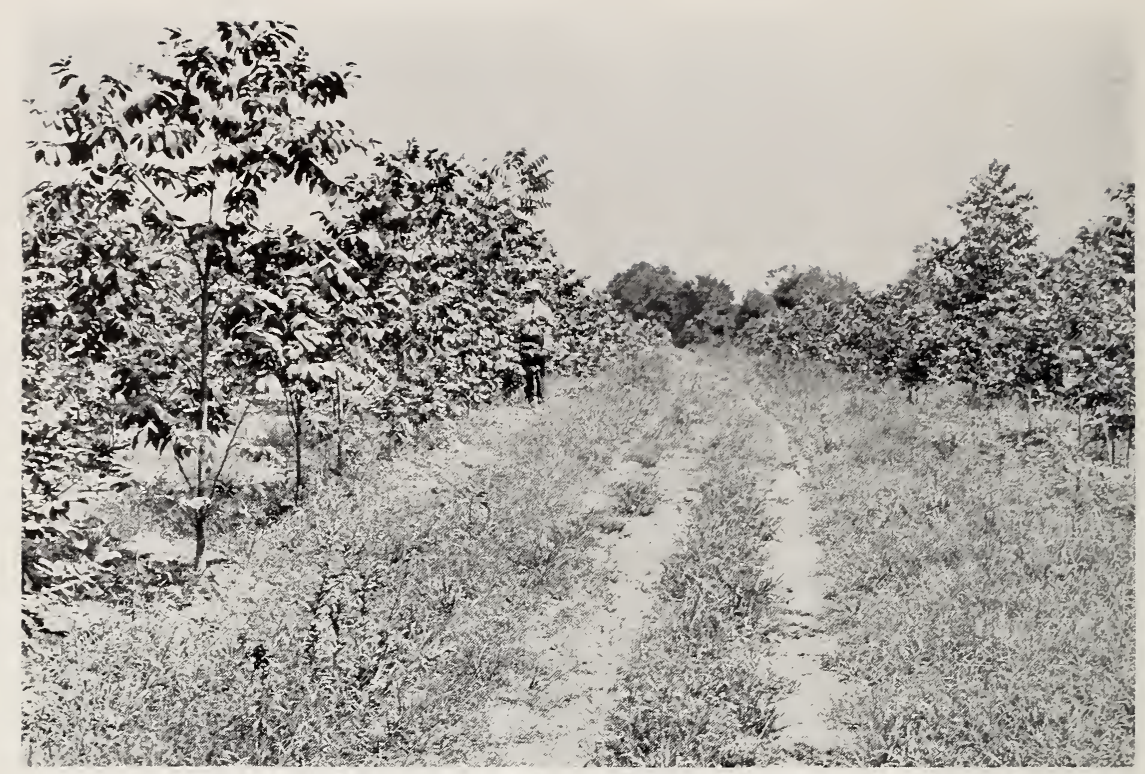

Part of Main Avenue through Nurseries

\section{Arrowfield Nurseries}

Pioneers in the propagation of hardy Pecan trees for northern planting. Introducers of the important northern varieties of Pecans, and growers of hardy Pecan and Walnut trees on northern stocks under northern conditions.

Growers also of all the leading southern varieties of Pecans, as well as of other nut trees.

Arrowfield Nursery Company, Inc. PETERSBURG, VIRGINIA 


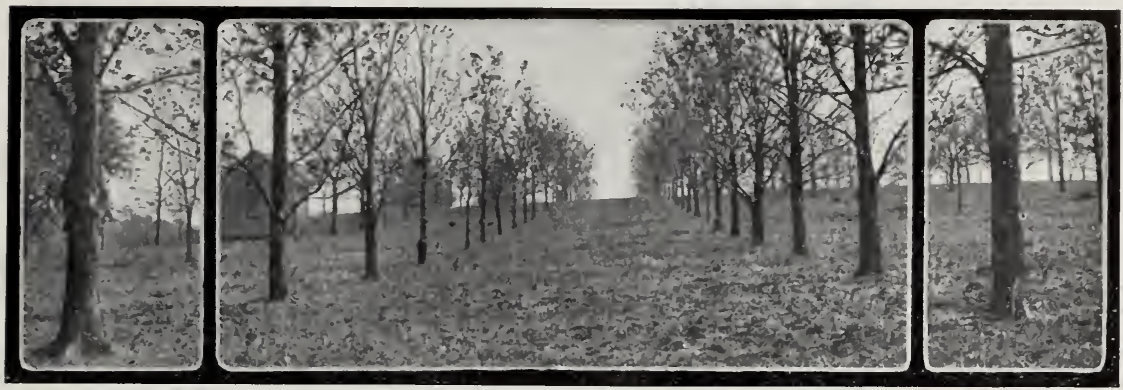

\section{Introduction}

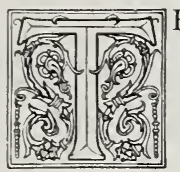

HE production of Pecan trees that will not only be hardy in northern climates but will fruit and mature their fruit in the shorter northern seasons, is a work to which we have given our careful attention for several years. We have introduced important northern varieties, conducted extensive experiments and made diligent investigations relating to the work in all its various phases. Much has been accomplished, and marked success in many ways has come as a result of the efforts made to effect this very desirable achievement.

Pecan trees grown in our nurseries have been transplanted in widely separated localities north and west, and have gone through rigorous winters without injury. They are succeeding well in localities where, a few years ago, there was little idea that trees which would yield choice Pecans could ever be grown. Already large orchard plantings are projected in northern districts, and will be made as soon as suitable trees in sufficient numbers can be had. We believe that planters can reasonably expect hardy varieties properly grown and planted in the North to give results that will compare favorably with results from southern sorts planted in the South.

Nursery production of Pecan trees in the North is attended with more difficulties and greater cost in the present stage of development than in the South, but for transplanting in the localities for which they are grown, these trees have a distinctive value which many times exceeds the additional cost.

While we have devoted so much attention to the production of hardy Pecan trees, we have also kept in the closest touch with the growing of leading varieties of nut trees in all the states, and to the growing of our trees always apply the very best methods known to this work. The northern types and varieties are supplied from our nurseries at Petersburg, Virginia, where severe climatic tests prevail, and trees for southern planting from our branch nursery at Cairo, Georgia, where conditions of soil and climate are ideal for the work. The most rigid standards are observed and careful attention given to digging, packing and to every other detail that will insure the delivery of the highest grade trees.

\section{ARROWFIELD NURSERY CO., Inc.,} Petersburg, VA. 


\section{PECANS}

Combining, as it does, the requisites of an excellent shade and ornamental tree with the production of a nutritious and valuable food material, the Pecan must be regarded as one of America's most valuable trees. It is very hardy, belongs to the hickory species, grows to immense size, and when established in favorable surroundings, lives for centuries. As a shade tree it has few equals.

It is found as a forest tree in the Mississippi Valley, and the Wabash bottoms, and is native as far north as Davenport, Terre Haute, and Cincinnati, and west to the head waters of the Colorado river. The area in which it is indigenous embraces portions of Iowa, Illinois, Indiana, Ohio, Missouri and Kentucky, in addition to the southern states. It has also been transplanted and grows well in sections far from its native home. With the introduction of hardy varieties, originating in northern localities, capable of withstanding severe winters and producing regular crops, Pecan-growing is being carried far northward, and the cultural range extended to parts of most of the states in the union. The Indiana and the Busseron, natives of the state of Indiana; the Major and the Hinton, natives of Kentucky, and the Mantura and the Appomattox, two hardy Virginia varieties, are especially adapted to northern planting, when grown on right stocks under suitable climatic conditions. Of the southern varieties, Stuart, Van Deman and Moneymaker are worthy of trial in the North.

Very great interest in Pecan-growing is manifested throughout the northern and western states, where many beautiful, symmetrical, hardy and prolific specimens of Pecan trees are being found bearing thin-shelled nuts, free from any injury by severe winters. Among these trees is one at Lebanon, Ohio, eighty years old, measuring 4 feet in diameter, 12 feet from the ground, with a spread of top of 80 feet, bearing annual crops of thin-shelled nuts.

\section{A Profitable Industry}

The modern methods of propagating and cultivating Pecan trees, and the introduction of varieties that come into bearing in from six to eight years, have shortened the waiting period, heretofore the only barrier to Pecan planting, and have opened up

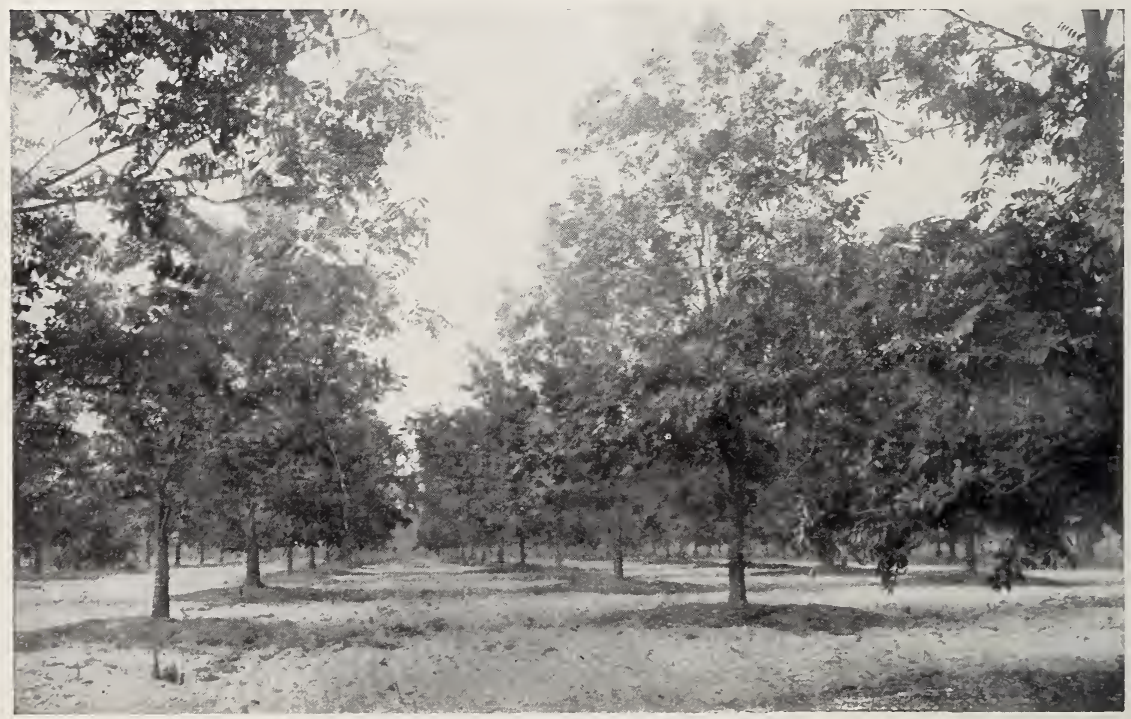

Scene in a well-kept Pecan Grove 


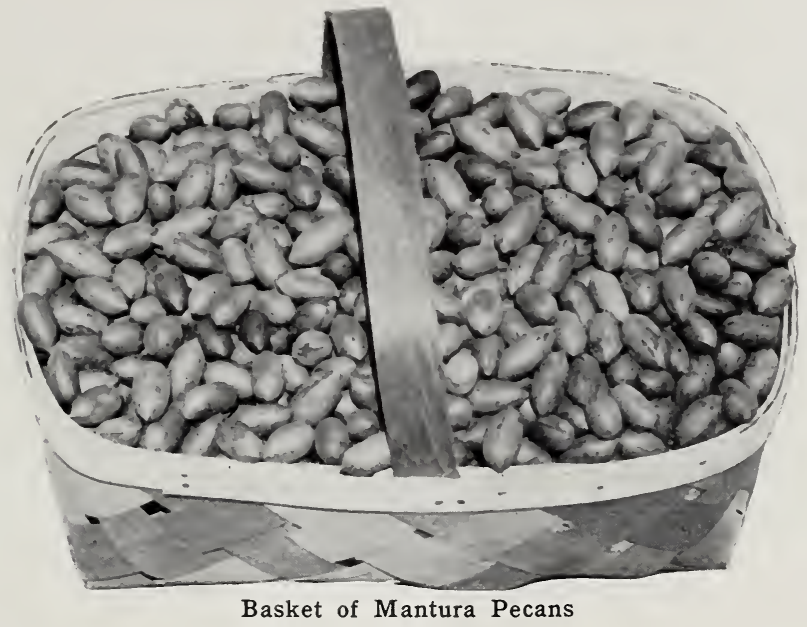

a highly profitable industry, which, though comparatively new, is rapidly becoming one of importance throughout America. Large commercial orchards have been planted from Virginia to Texas and many of these are now bearing heavy crops of choice nuts which yicld large profits to their owners. Extensive orchard plantings will be made in northern localities as soon as the supply of hardy trees is sufficient to meet the requirements.

Pecan orchards come into bearing about as soon as apple orchards, and nuts, unlike apples, do not require careful picking, handling and storing. Many years will pass before the product will equal the demand. Pecans are grown only in this country, and the improved varieties are just beginning to reach the trade. The nuts are the richest and finest flavored that find their way to the markets. The person who has eaten the full-meated "nutty" kernel of a Stuart, Van Deman or Mantura Pecan would not recognize it as being of the same species as the hard-shelled, painted scedlings usually found at the stores.

\section{Selection of Varieties}

One of the most important points to be observed in planting Pecan trees, if the highest success is to be obtained, is the selection of varieties. This important matter often gets little or no attention from those making small plantings of a few trees to a hundred or more. The mere name "budded" or "grafted" means, to many persons, all that is to be desired. There are more than a hundred named varieties of Pecans, but only a small number out of this list should be selected for general planting. Of paramount importance is the adaptability of the variety to the locality in which it is to be grown.

As to the fruit, the medium-sized nut is more often found to meet the demand. It is nearly always more certain in bearing, generally superior to the larger types in flavor, better in filling quality and thinness of shell. The very large nut is frequently shy in bearing, deficient in development of kernel, poor in quality and otherwise defective.

\section{Soils}

Pecan trees will succeed on a wide range of soils-sandy and clay, river bottoms subject to overflow, flat woodlands, low hammocks and high sandy ridges of pine land. They will do well on all except wet, undrained soils, or land closely underlaid with rock. A good loamy soil, resting on a medium clay sub-soil, is ideal for the Pecan. 


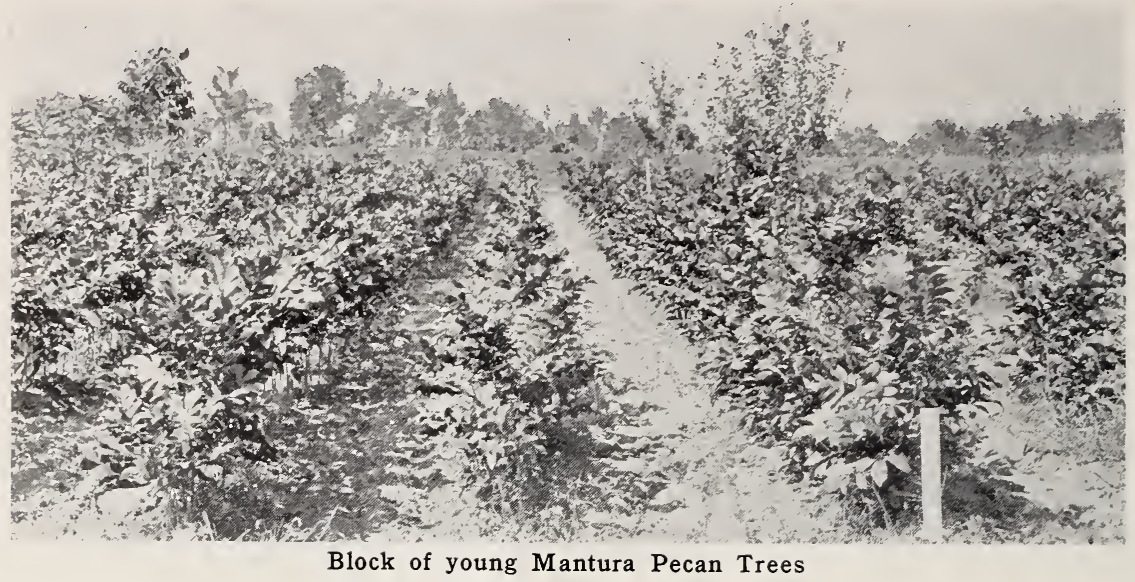

\section{Transplanting}

Late fall and early winter are the best seasons for transplanting Pecans, but they

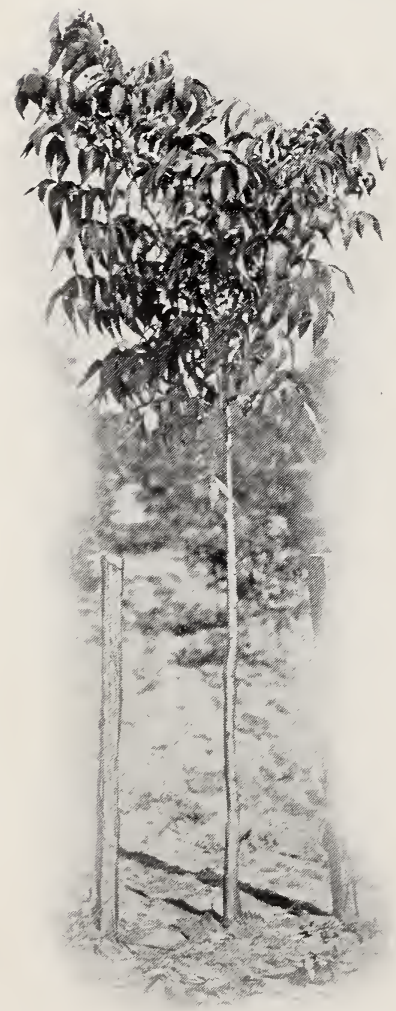

Mantura trees in orchard One-year's growth may also be planted in the early spring. In this case it is best to have the trees shipped during early winter, heeled in carefully and protected from the sun until the season becomes favorable for transplanting them in their permanent positions.

Pecan trees, in orchards, should be planted about 50 feet apart each way, or seventeen trees to the acre, on average soils. Sixty or even a hundred feet might be better for rich alluvial lands.

Transplanting Pecans requires more care than that given fruit and ordinary shade trees, on account of the long tap-root, but with trees properly dug and packed, and carefully set out at the right season, there need be no fear that they will not live. No harm is done to a Pecan tree by cutting the tap-root. As soon as the tree is transplanted it begins to send down other taproots, and at the end of a season's growth they have penetrated deep into the soil.

\section{Culture}

No trees respond more promptly to good culture and fertilization than Pecans. Where they are planted in gardens and lawns the weeds and grass should be kept down around them, either by hoeing or by mulching with straw or stones, so as to keep the soil in such condition that it will retain moisture. In fields, the cultivation of the crops will be sufficient culture for the trees, except an occasional hoeing around them. Farm and vegetable crops can be grown among the trees for many years. The roots go deep down into the earth, and as they do not rob the surface soil of moisture and fertility as do most trees, crops can be grown close to them. 


\section{Pecans as Shade and Ornamental Trees}

If there were no fruit to be had from the Pecan tree, its hardiness, its long life, its beautiful dark green foliage, its gray trunk and rugged branches, its wide-spreading. leafy top, objects of beauty in any landscape, would alone commend it for planting throughout the country wherever large, symmetrical trees are desired for shade or ornament. The Pecan tree likes company, and there is no more congenial place for it than in yards, lawns and gardens. It is comparatively a rapid grower and grass will keep green up to the very trunk. The illustration on this page shows a young Pecan tree at Petersburg, Virginia, grown from a small tree, a "mere switch," transplanted five years; and represents the average size of ten Pecan trees transplanted on this city lawn at the same time. This tree is 30 feet high with a proportionate spread of branches.

On the back cover page is an illustration of another Pecan tree in Virginia grown for shade and ornament. How well it fills the purpose, a casual glance will tell. In addition, both these trees drop choice fruit annually to the delight of the children and their parents.

\section{Producing Hardy Pecan Trees}

Diligent investigations and careful experiments have led us to the conclusion that to obtain the best success in growing Pecan trees in northern climates, the varieties must not only be hardy, but must be "budded" on hardy stocks from northern Pecans, and grown under northern conditions. Our work has been conducted in accordance with this conclusion, and there

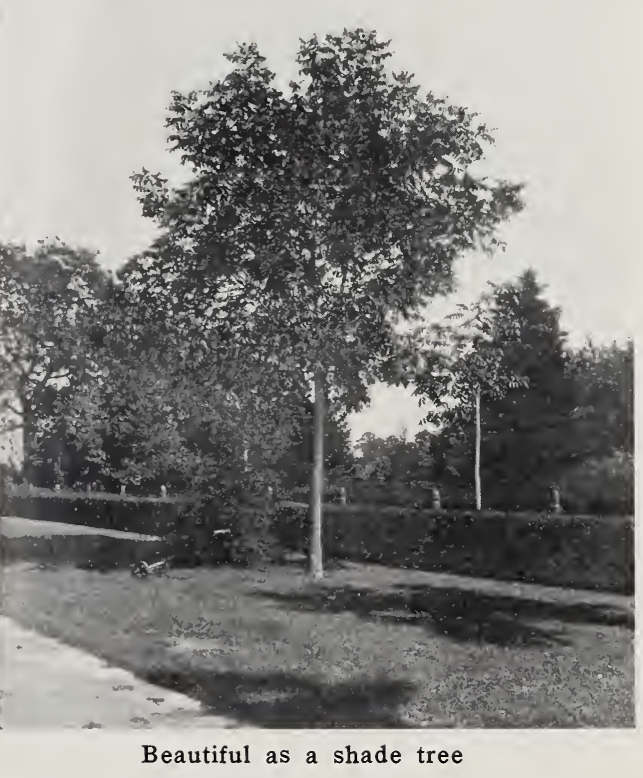
has been no reason thus far to modify it in any way. We grow no "root-grafted" trees except for experimental purposes.

Our first planting, made in 1905, consisted of a choice lot of Pecans grown in Indiana, being the first nursery planting of northern Pecans. Trees from these nuts become dormant earlier in the fall and remain dormant longer in the spring than trees from southern nuts. This planting was followed the next year by five hundred pounds of northern and southern nuts; the third year by two thousand pounds, and large plantings have followed annually until our nurseries now contain more than a hundred thousand Pecan stocks, most of which are from northern-grown Pecans. 


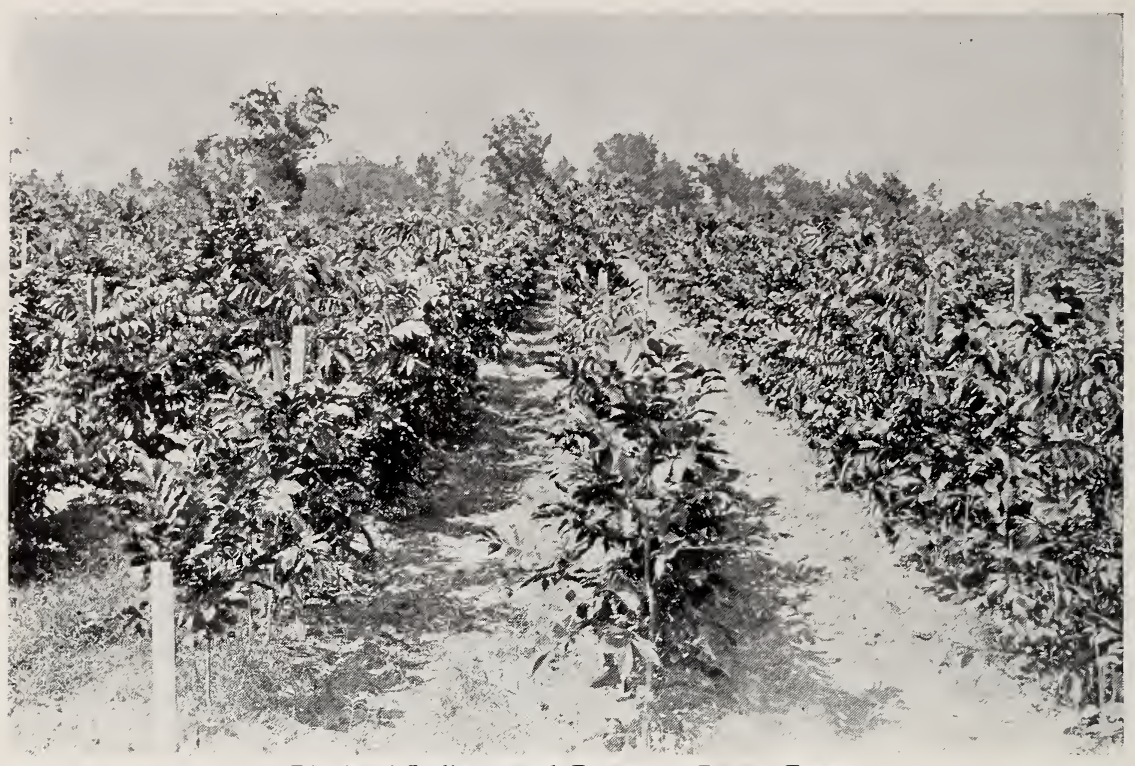

Block of Indiana and Busseron Pecan Trees

\section{Six Hardy Pecans}

Meantime the search for hardy varieties was being vigorously conducted. All the available cultivated varieties at that time had originated in the far South. In I906, out of a large number of promising Pecans that were investigated, two in Virginia were found eminently worthy of propagation, and these, the Mantura and the Appomattox, were introduced in that year. Two years intervened before we found any other varieties meeting the requirements of the standards we had set for them. Two small, but very choice, Pecans were found in northern Kentucky in I908. The original trees were visited, their hardiness and bearing qualities established, and the Major and the Hinton were then introduced and their propagation begun. During the same year Mr. Mason J. Niblack brought to attention two excellent Pecans in Indiana, and these two varieties, the Indiana and the Busseron, somewhat larger than the two Kentucky Pecans, were added to the list, making six hardy Pecans available for northern planting.

Southern varieties that give most promise in northern territory were also being investigated, and of those tested, the Stuart, Van Deman and Moneymaker were found to possess characteristics that make them worthy of trial in northern localities.

\section{Extensive Nursery Plantings}

In our work we have produced more than 50,000 seedling Pecan trees, one to six years old, grown from Indiana nuts, and several hundred trees of northern varieties budded on northern stocks. We have never found a single tree winter-killed. Of the same number of Pecan stocks grown from southern seed, practically all showed signs of winter-killing.

Nursery-grown Pecan trees in the North require special attention from seeding and budding time to digging and packing. The bud unions must be perfect, the trees must have proper roots; these must be carefully dug and the trees properly packed. It is to these and many other important details that we give special attention. 


\section{Trees for Northern Part of Pecan Area}

In addition to the Pecan trees grown especially for the far North, it has been our aim to produce trees of the leading southern varieties that would be specially adlapted to planting in the northern part of the area adapted to southern varieties. For this purpose we have established a large grove at Petersburg, consisting of several hundred trees of the leading southern Pecans. These trees have been growing in this climate for several years. From only the best and most vigorous trees we take buds and insert these on stocks from seed that have grown in such latitude as best fits them for the locality in which they are to be transplanted. The varieties that we grow most largely for this purpose are Stuart, Van Deman and Moneymaker. We are now testing out other varieties.

\section{Southern Branch Nursery}

For southern planting we grow the trees at our branch nursery at Cairo, Ga. Here is every facility for producing the very best Pecan trees. Careful attention is given to the work by men of long experience. The leading southern varieties are grown in this nursery in large numbers to meet the needs of those making extensive orchard plantings. The splendid root system, the care taken in digging and the atten-

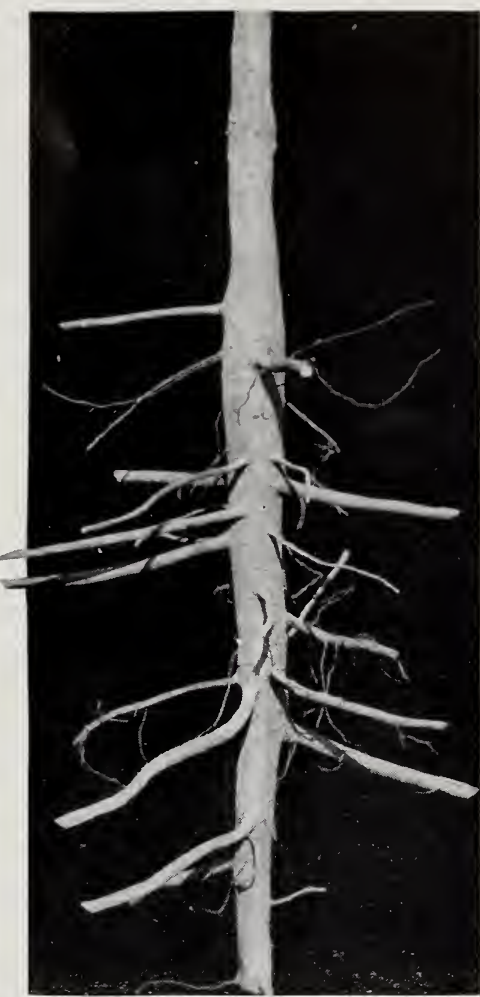

Good Root System tion given to packing, have won friends for these trees wherever they have been planted.

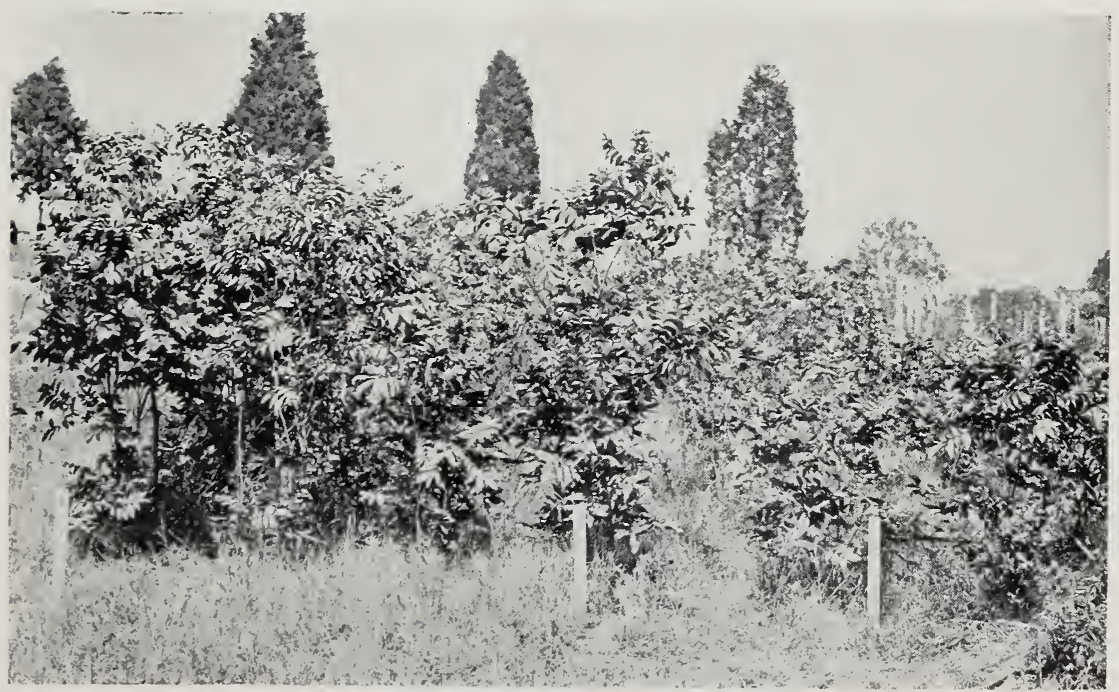

First Pecan Nursery planted with northern nuts 


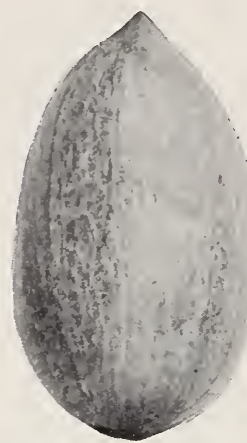

Stuart

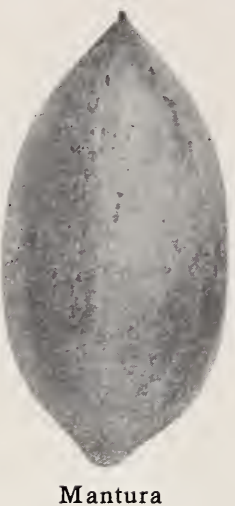

Mantura

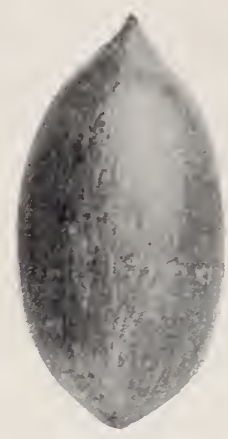

Appomattox

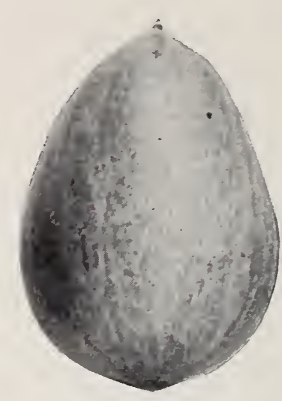

Moneymaker

\section{VARIETIES OF PECANS}

MANTURA. The original tree of the Mantura Pecan is growing in Surry county, Virginia, and is one of four trees from nuts which grew at Surry courthouse. The Mantura tree is a large, symmetrical specimen, with wide-spreading branches. It is about 80 feet high and measures I I feet around the trunk. It has been bearing for eighteen years. The particular strain from which this variety comes has been growing in Virginia for more than sixty years. The nut is large, shell very thin, kernel dark straw-colored with a sweet, nutty flavor. The Mantura is described in the Yearbook of the United States Department of Agriculture for 1907, page 319. This variety has been planted as far north as Canada and west to Missouri. All reports thus far received as to its behavior have been favorable. Top-worked trees have begun to bear the second year from insertion of the bud. The tree is hardy, vigorous and a fast grower.

APPOMATTOX. The original tree of the Appomattox Pecan is at Petersburg, Virginia. It is about thirty-five years old and has been bearing for fifteen or twenty years. The nut is medium-sized, with thin shell; the kernel is plump, and the flavor excellent. In quality of kernel, according to a well-known expert, it compares with the San Saba, the choice Texas variety, which is a standard of quality among Pecans. The original tree is an exceedingly regular bearer and very hardy. Top-worked trees have borne crops the third year. There is every reason to believe that the Appomattox will give the same satisfaction as the Mantura. It is growing throughout the same area as Mantura.

BUSSERON. This variety originated in Knox county, Indiana. The parent tree measures 9 feet in circumference and is about 75 feet tall. It is a beautiful specimen, well branched and symmetrical, and is a prolific bearer each season. The nut is medium-sized, very uniform, and is one of the largest of the far northern types. The kernel is solid, fine-grained and of excellent quality. This variety is exceedingly hardy and should bear regular crops in localities far northward, when the young trees are properly grown under right climatic conditions. The Busseron, together with Indiana, Major and Hinton, are commended for planting in extreme northern areas within the Pecan range. All these varieties are thin-shelled.

INDIANA. This variety, like the Busseron, originated in Knox county, Indiana. The original tree is about 5 feet in circumference and 60 feet high. The nut is mediumsized, and like the Busseron, the texture is solid, fine-grained, sweet, nutty, and of good quality. The nuts of these varieties are strikingly alike in every respect. The Indiana is being as extensively planted as the available supply of trees will permit. It is a very desirable northern type. 


\section{VARIETIES OF PECANS, continued}

MAJOR. The parent tree is in a large grove in Henderson county, Kentucky. It bears regularly and well, and the nuts are always well filled. The cracking quality is excellent, the kernel coming out perfectly whole in almost all cases. The nut is small but the kernel is of fine quality. It is a type, which, when a sufficient supply is available, will be in large demand by confectioners. The trees are very hardy.

HINTON. This variety also originated in the large grove in Henderson county, Kentucky. In shape it is attractive and peculiarly distinct. The nut is medium-sized, being somewhat larger than the Major. The half-kernel is almost circular and of light brown color. The quality is good. The trees are hardy and vigorous, with large, dark green leaves. It is a choice variety for both domestic and commercial purposes.

STUART. This is a Mississippi varicty, the parent tree growing in a garden at Pascagoula. The Stuart succeeds over a wide range of territory and is the most popular and most largely planted of all the southern varieties. The nut is large to very large with a kernel of good quality.

VAN DEMAN. The original tree stands, thrifty and vigorous in St. James Parish, Louisiana, bearing very heavy crops annually. The nut is very large and the kernel has a rich, delicate flavor. It is being largely planted both on home grounds and in commercial orchards. It is a very choice Pecan.

MONEYMAKER. The Moneymaker originated at Mound, Louisiana, considerably north of the locality in which the Van Deman tree is growing. It is a precocious, prolific and hardy varicty. It transplants well, makes a vigorous growth in northern sections and has proved hardy as far north as Illinois. The nut is medium-sized, shell medium in thickness, and the kernel of good quality.

The Stuart, Van Deman and Moneymaker are three southern varieties especially commended to persons desiring to plant some of the southern pecans in northern area.

\section{Other Varieties}

Among the other varieties largely planted throughout the South are: Alley, Bradley, Curtis, Delmas, Frotscher, Moore, Nelson, Pabst, President, Russell, Schley, Success, Teche and Waukeenah.

\section{The Pecan and Its Culture \\ By HAROLD HUME}

To supply reliable information on Pecan-growing, this up-to-date work, touching every cultural detail, has been prepared after several years' careful study by the author who is recognized as an authority. The book is thoroughly practical and contains information needed by every grower of Pecans, large or small. The second edition has

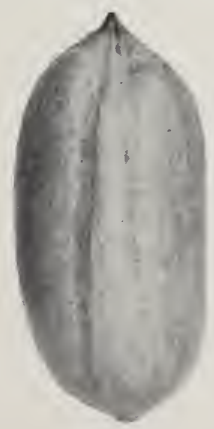

Busseron been almost entirely rewritten and much enlarged. It contains 195 pages, 75 illustrations cloth bound; price, $\$ \mathbf{I} .5^{\circ}$ postpaid.

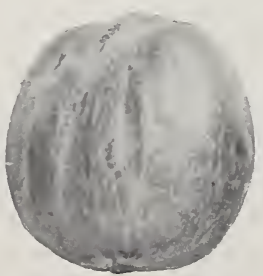

Hinton

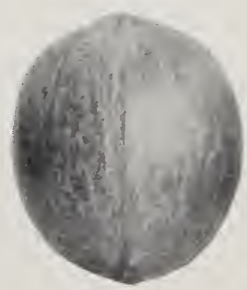

Major

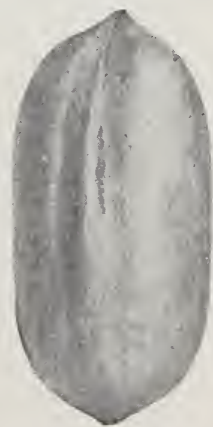

Indiana 


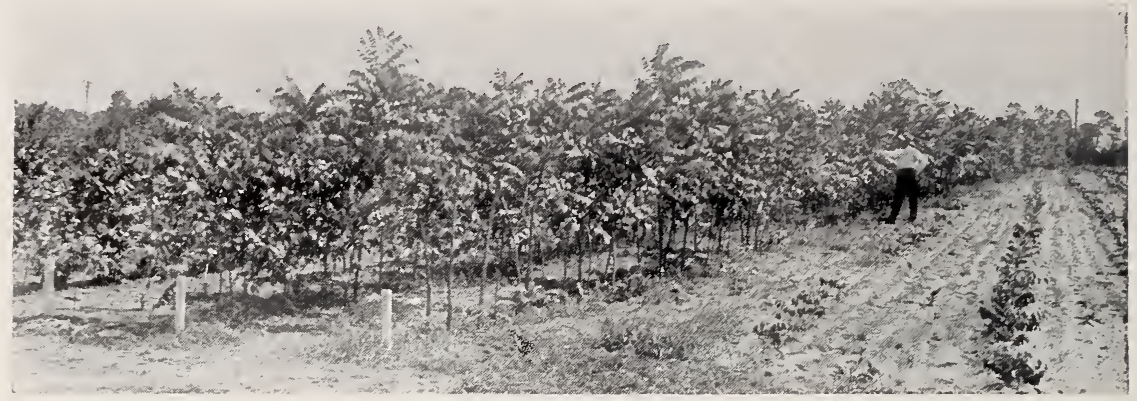

Rush Walnut Trees

\section{Persian (English) Walnuts}

Cultivated Walnuts were among the very early introductions from Europe to America. As they were probably brought here first from England they were given the name "English Walnuts," although incorrectly. When the Romans colonized Britain, they brought this nut from Italy and planted it there. It was carried to England from Italy and to Italy and Greece from Persia. Its native home, so far as may be known, was along the Caspian Sea, and the name "Persian" is very fitting.

It is a fine, lofty-growing tree, with beautiful symmetrical head, and is exceedingly handsome for lawns. The trees are decidedly ornamental with their light gray

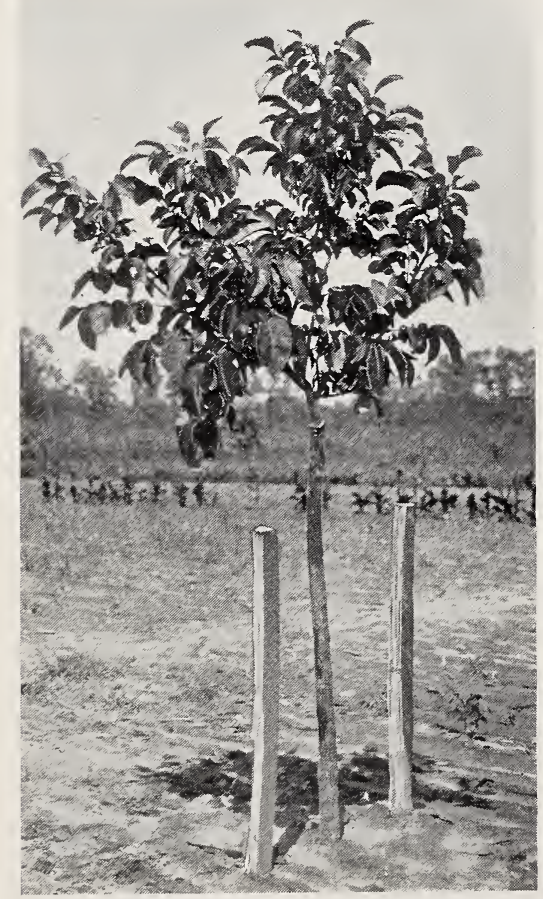

Rush Walnut budded on Eastern Black Walnut root. Second year transplanted bark and dark green foliage.

The greatest commercial success with Walnut culture has been in California. The people of Washington and Oregon are just awaking to the fact that Walnuts of the best quality can be grown in these states; and in Idaho and British Columbia there are abundant evidences of success.

With proper attention to varieties and culture, Walnut-growing can be made a profitable industry in the states east of the Rocky mountains as well. The lack of attention given the industry on the Atlantic coast is due largely to the fact that seedling trees, besides failing to reproduce in kind, vary so much in vigor, hardiness and productiveness that their culture is uncertain, and the trees have been found difficult to propagate by budding and grafting. But budded or grafted trees must be set out to insure success and the stock should be the Eastern Black Walnut. By using this as the stock on which to propagate the Persian types, the trees are more vigorous, adapt themselves to a wider range of soils, and ripen their wood earlier and better in the fall, and thus withstand, without injury, very low temperatures. 


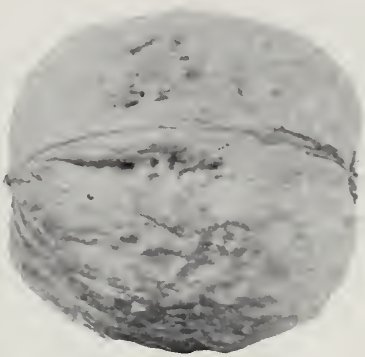

Rush Walnut

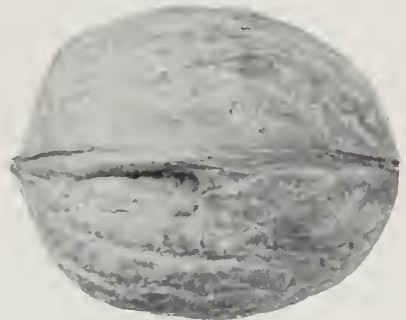

Pomeroy Walnut

\section{PERSIAN (ENGLISH) WALNUT, continued}

In Maryland, New Jersey, Pennsylvania and New York, Walnut-growing is already assuming considerable importance. There have been trees of the Persian Walnut growing for hundreds of years in the Atlantic states, and some of them have attained great size and age. Within a few years this valuable and nutritious nut will be grown in many parts of America where not a single Walnut tree is now to be found. They promise well for the fruit-belt in Michigan eastward, and for the elevated portions of the southern states northward to the New England states.

The Rush is one of the best of the hardy and productive varieties. It was originated in Pennsylvania by Mr. John G. Rush.

The Pomeroy is another hardy eastern Walnut, which has been bearing many years in western New York.

The Mayette, Franquette and Parisienne, are choice Pacific coast varieties.

We are devoting our attention especially to the eastern varieties. All our trees are budded on vigorous Black Walnut stocks.

\section{Japan Walnuts}

During the short period which has elapsed since Japan Walnuts were introduced into this country, they have been quite generally planted, not in specially large numbers, but in lots of a few trees in various sections. The two species most common are Juglans Sieboldiana and Juglans Cordiformis. The meat is rich and well flavored, and the nuts much superior to our native Black Walnuts. The shells are rather thick. For the home grounds and orchards the Japan Walnut is a very valuable tree and well worth planting. Its broad, round head and large dark green foliage make it an exceedingly attractive ornamental. It should be set in welldrained soil, and can be grown in nearly all parts of the United States.

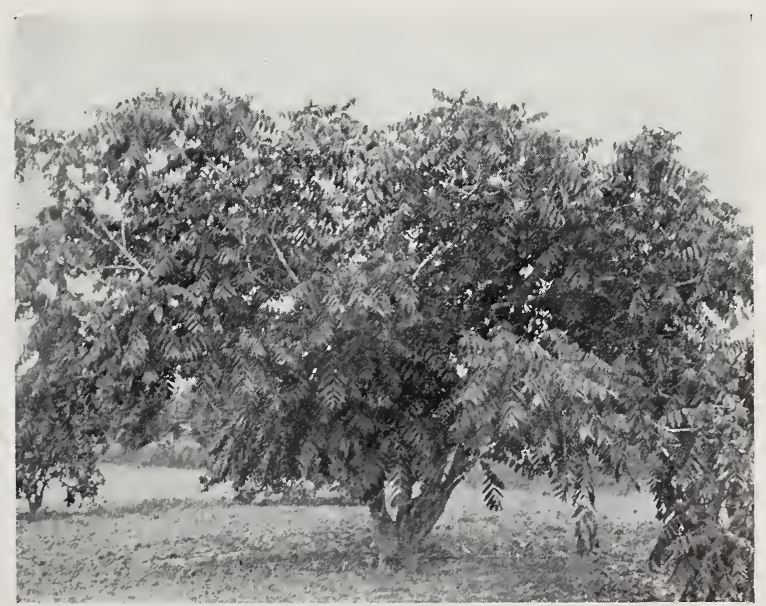

Japan Walnut (Juglans Sieboldiana) 


\section{Chestnuts}

The Chestnut is a rapid-growing, handsome tree, attaining large proportions when sufficient room is allowed for its development; and its dark, rich, waxy-green

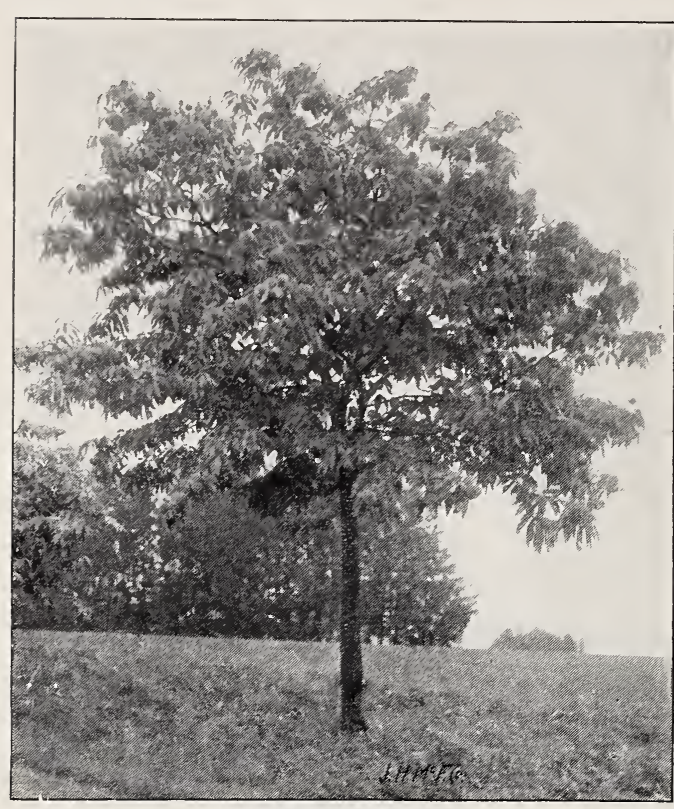

Chestnut Tree foliage makes it a beautiful tree for planting in lawns or gardens, along avenues, roadsides and in parks.

It thrives best on high, welldrained soil, and grows from Maine to Florida and from the Atlantic coast to the foothills of the Pacific slope. It finds especially congenial soil and climate along the Blue Ridge and Alleghany mountains and does well at an altitude of three thousand feet.

Chestnut culture is now receiving considerable attention and is being engaged in with profit when intelligently conducted. The demand for the larger nuts has stimulated their production and trees are being widely grown. Their hardiness and adaptability to different climates commend them for general planting. Orchards are possible not only where native Chestnuts flourish but in many localities where native trees do not occur.

The Paragon is a choice, large variety, hardy and prolific. The trees of ten begin to bear when two and three years old.

The American Sweet is a small nut but the sweetest flavored of the varieties and forms an important item of commerce.

\section{Butternuts}

Throughout the northern part of the United States and Canada, and extending as far south as Arkansas, grows the Butternut. The tree is a comparatively rapid grower, begins to yield a few years after transplanting and frequently grows to enormous size. It is an attractive tree for lawn or landscape or for orchard planting. The wood is valuable for ornamental cabinet work and the nut, rich in oil, is excellent for eating purposes. It has a richenss and a flavor peculiar to itself. An oil highly desirable for lubricating delicate machinery is made from the nuts. They sell from $\$ 1$ to $\$ 2$ per bushel, and the supply is insufficient to meet the demand in large cities. The Butternut tree will grow with but little attention and yield abundantly.

\section{Filberts}

Filberts may be described as large shrubs or low trees. They thrive best in a warm, moderately moist, loamy soil, with a dry subsoil which will prevent excessive wood growth. They will grow at elevations of five or six thousand feet. 


\section{Offerings}

From our nurseries at Petersburg, Virginia, we can supply the hardy varieties of pecans on hardy stocks, northern grown; southern varieties grown especially for planting in the northern part of what is usually known as the "pecan area;" the eastern, hardy types of Persian (English) walnuts on vigorous black walnut roots and other varieties of pecan, walnut and other nut trees.

From our Branch Nursery, at Cairo, Georgia, we can supply, in large or small quantities, all the leading varieties of pecans for planting in the South.

\section{LARGE NUT TREES}

We make a specialty of Pecan and other nut trees for prompt effect and results in yards and lawns, and can supply large, sturdy, thrifty specimens for this purposetrees that will delight those who plant them. Special attention is given these trees in the nursery, and to digging and packing them that they may have greater value and vigor when planted in their permanent locations, start promptly to growing and bear fruit earlier than would younger and smaller trees.

\section{PRICES}

Write us for price-list and any information desired in regard to pecan and other nut trees. We shall be glad to have correspondents state the localities in which trees are to be planted; also the number of trees desired.

\section{ARROWFIELD NURSERY CO., Inc., Petersburg, Va.}

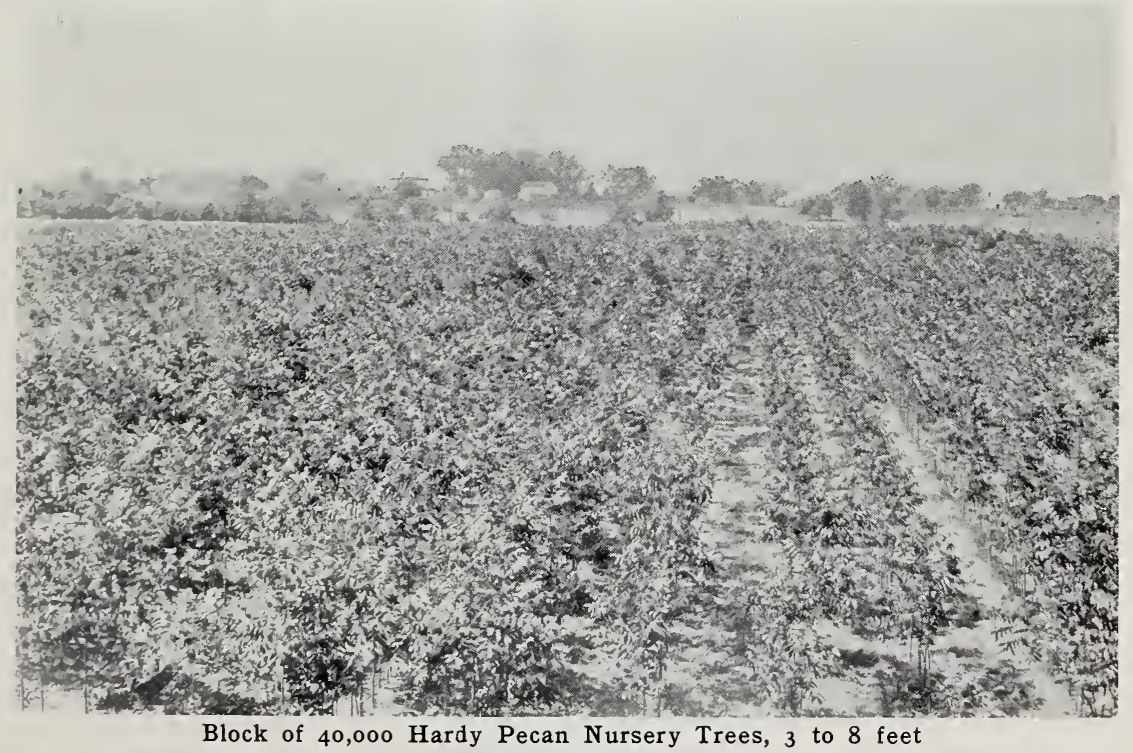

J. Horace McFarland Co., Horticultural, Printers, Harrisburg, Pa 


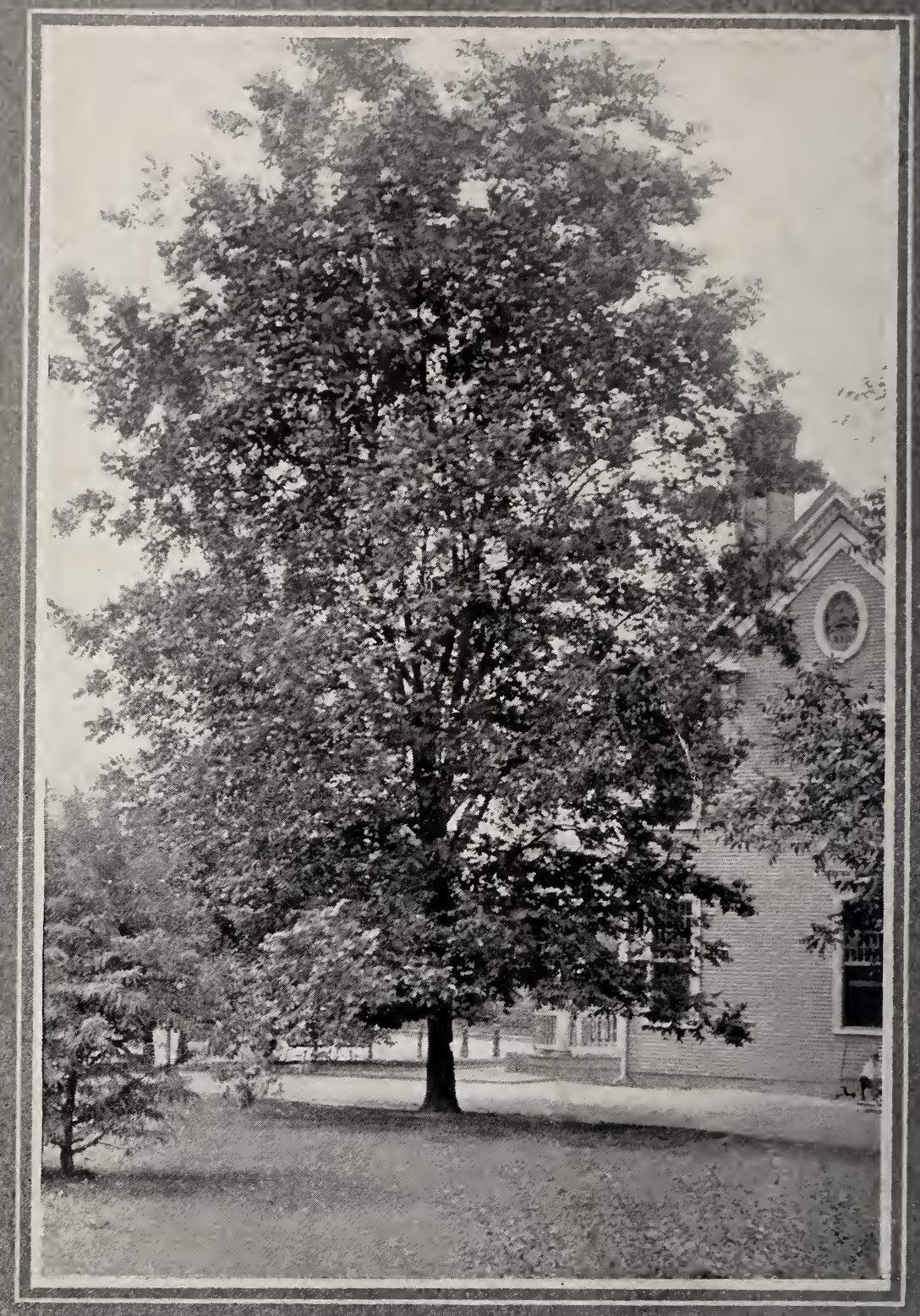

\title{
ARROWFIELID NUTSERIES
}

\author{
Petersburg, Virginia
}

